\title{
Pancytopenia in Propionic Acidemia: Hematologic Evaluation and Studies of Hematopoiesis in Vitro ${ }^{1}$
}

\author{
LINDA C. STORK, DANIEL R. AMBRUSO, STEPHEN F. WALLNER, JAMES E. SAMBRANO, \\ LYNN C. MOSCINSKI, HARRY L. WILSON, AND EDWARD R. B. MCCABE \\ Departments of Pediatrics; Pathology; Medicine; and Biochemistry, Biophysics and Genetics, University of \\ Colorado Health Sciences Center, the Department of Medicine, Veterans Administration Hospital, and Denver \\ Children's Hospital, Denver, Colorado 80262
}

\begin{abstract}
This study investigated the hematologic abnormalities of an infant with propionic acidemia and reversible pancytopenia. Light and electron microscopy of her bone marrow revealed severely disturbed cellular morphology with trilineage dysmyelopoiesis, hemophagocytosis, and numerous multinucleated histiocytes and megakaryocytes. The effects of her serum and of organic acids associated with propionic acidemia were studied on hematopoiesis in vitro. Mouse erythroid (CFU-E) and granulocyte-monocyte colonies (CFU-GM) were assayed by fibrin clot technique; human CFU-GM were grown in agar culture. The infant's serum reduced mouse CFU-E and CFUGM by 43 and $32 \%$, respectively, compared with normal human sera, but had no effect on human CFU-GM in our culture system. Buffered propionic acid caused concentration-dependent inhibition of mouse CFU-E and human CFU-GM over a range reported in sera of acutely ill infants with propionic acidemia. Neither cell viability nor subsequent colony formation was diminished by preincubation of bone marrow cells with propionic acid for $48 \mathrm{~h}$. The three other organic acids studied, tiglic acid, 3-OH propionate, and glycine, did not inhibit growth of mouse CFUE, CFU-GM, or human CFU-GM, and glycine significantly enhanced formation of the latter. Evaluation of the infant's hematologic abnormalities suggests that inhibition of bone marrow proliferation and maturation and, perhaps, shortened red blood cell survival were responsible for her pancytopenia. The studies performed in vitro implicate propionic acid in this hematopoietic dysfunction. (Pediatr Res 20: 783-788, 1986)
\end{abstract}

\section{Abbreviations}

CFU-E, erythroid colony-forming units

CFU-GM, granulocyte-monocyte colony-forming units

BM, bone marrow

EM, electron microscopy

PA, propionic acid

Received September 23, 1985; accepted April 7, 1986

Address correspondence and reprint requests to Dr. Linda C. Stork, Department of Pediatrics (C-220), University of Colorado Health Sciences Center, 4200 E. 9th Avenue, Denver, CO 80262

Supported by the Stacy True Memorial Fund; Bonfils Memorial Blood Center; USVA Grant 9205; Grant RR-69 from the Clinical Research Centers' Program of the Division of Research Resources; MR Center Grant 2-PO-HD04024 from the National Institute of Child Health and Human Development, National Institutes of Health; and by a Regional Biomedical Diagnostic and Treatment Program Grant (SPRANS, MCJ-000252) from Maternal and Child Health, the Bureau of Health Care Delivery and Assistance.

Presented in part at the Society for Pediatric Research National Meeting, San Francisco, CA, May 4, 1984.

\author{
3-OH PA, 3-OH propionic acid \\ CSA, colony stimulating activity \\ $\mathrm{Hgb}$, hemoglobin \\ WBC, white blood cell count \\ LDH, lactate dehydrogenase \\ PCM, placenta-conditioned medium \\ MNC, nonadherent mononuclear cells
}

Hematologic abnormalities occur in certain inborn errors of amino acid metabolism. Reversible neutropenia, thrombocytopenia, and, rarely, pancytopenia have been described in a number of children wtih methylmalonic, isovaleric, and propionic acidemia (1-3), but the underlying hematologic defects responsible have not been widely investigated. Recent studies by Inoue $e t$ al. (4) and Hutchinson et al. (5) suggest that inhibition of BM stem cell proliferation by the excess organic acids may be involved. In the present study, we examined the hematologic abnormalities of an infant with propionic acidemia and investigated the effects of certain organic acids associated with propionic acidemia on hematopoiesis in vitro.

\section{CASE REPORT}

E. B., a 31-day-old black female was admitted to the pediatric service following 7 days of vomiting, increasing somnolence, and one episode of hematemesis. The child was the $3.76 \mathrm{~kg}$ product of a normal pregnancy with poor weight gain since birth. She was lethargic, hypotonic, and pale on admission without fever, lymphadenopathy, hepatosplenomegaly, petechiae, or purpura. Laboratory evaluation included a $\mathrm{Hgb}$ of $11.7 \mathrm{~g} / \mathrm{dl}$, reticulocyte count of $0.2 \%$, and a negative direct and indirect antiglobin test. Her WBC was $3400 / \mu$ l with $17 \%$ polys, $1 \%$ bands, $66 \%$ lymphs; platelet count was $18,000 / \mu$ l. Serum bicarbonate, SGOT, SGPT, bilirubin, creatinine, and electrolytes were normal, as were the spinal fluid cell count, protein, and glucose. Serum ammonia was minimally elevated and $\mathrm{LDH}$ was one and a half times normal. Blood, urine, and spinal fluid cultures for bacteria and nasopharyngeal, urine, and rectal cultures for virus were negative.

Several days of persistent neutropenia, thrombocytopenia, progressive anemia, and the development of hepatomegaly led to further hematologic evaluation. The peripheral blood smear showed moderate anisocytosis and poikilocytosis of red cells with tear-drop forms, without fragments or spherocytes. White blood cells and platelets appeared normal. Light microscopy of the BM aspirate and biopsy revealed trilineage dysmyelopoiesis, hemophagocytosis, and numerous large bizarre multinucleated cells. Peripheral blood and BM chromosomes were normal. 
The diagnosis of propionic acidemia was made by gas chromatography mass spectrometry of the child's urine (performed in the laboratory of Dr. S. Goodman, University of Colorado Health Sciences Center, Denver, CO), which contained elevated levels of 3-OH propionate, methylcitrate, 3-OH-methylglutarate, and 3-methylglutaconate. The diagnosis was confirmed by demonstration of deficient activity of propionylCoA carboxylase in the infant's white blood cells and cultured skin fibroblasts as performed in the laboratory of Dr. B. Wolf, Medical College of Virginia, Richmond, VA.

She was begun on a diet restricting isoleucine, valine, threonine, and methionine. Because the addition of L-carnitine to the diet of a patient with propionic acidemia was reported to cause rapid clinical improvement (6), $100 \mathrm{mg} / \mathrm{kg} /$ day L-carnitine was added to the infant's regimen as well. Ten days from the start of this diet, the pattern of urinary organic acid excretion showed significant overall improvement and a $50 \%$ decrease in amount of $3-\mathrm{OH}$ propionic acid. At this time her platelet and WBC counts had returned to normal, the reticulocyte count was $3.7 \%$, and her BM morphology was only minimally abnormal. She was discharged 1 month after admission with an absolute neutrophil count of $4096 / \mu \mathrm{l}$, a platelet count of $350,000 / \mu \mathrm{l}$, and a $\mathrm{Hgb}$ of $8.7 \mathrm{~g} / \mathrm{dl}$ (see Fig. 1).

Two months later, following decreased oral intake, the infant again developed pancytopenia along with lethargy, vomiting, and increased excretion of urinary organic acids. At a routine clinic visit 5 days before this deterioration, her Hgb was normal although her WBC and platelet counts were mildly decreased (see Fig. 1). She had no detectable blood loss. BM morphology was nearly identical to that of the first aspirate. Pancytopenia rapidly resolved following further dietary manipulation. She has continued on a special diet with normal blood counts for over a year since diagnosis.

\section{MATERIALS AND METHODS}

Bone marrow histology and cytochemistry. BM aspirate and biopsy specimens were obtained from the infant's posterior iliac crest on days 3 and 11 of initial presentation and day 1 of relapse. Aspirates were stained with Wright's stain. Enzymatic staining for acid phosphatase and tartrate-resistant acid phosphatase, using naphthol AS-BI phosphate (Sigma, St. Louis, MO), and for nonspecific esterase with and without sodium fluoride, using $\alpha$-naphthyl butyrate (Sigma) and $\alpha$-naphthyl acetate (Sigma), were performed by standard techniques. One clot preparation was stained for lysozyme with the peroxidase-antiperoxidase technique and appropriate controls (Dako, Santa Barbara, CA). EM of the BM sample from day 1 of relapse was performed on

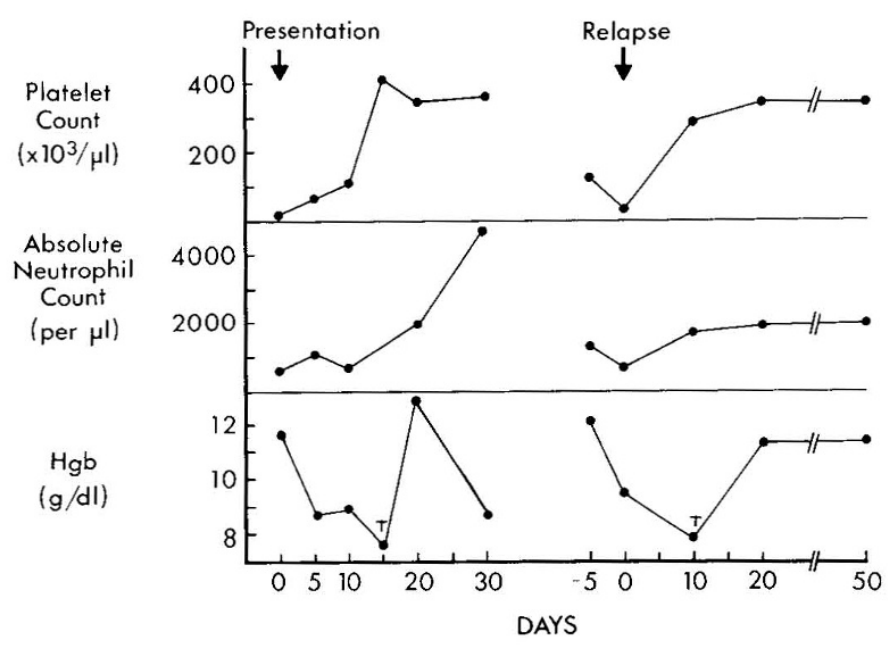

Fig. 1. Hematologic parameters during the course of the infant's illness. (Transfusion of packed red blood cells indicated by $T$.) glutaraldehyde fixed, lead osmium-stained sections using a Philips 201 transmission electron microscope.

Preparation of amino and organic acids. PA (Mann Research Lab, New York, NY) was diluted in either $0.2 \mathrm{M}$ sodium phosphate buffer, $\mathrm{pH}=7.4$, or supplemented McCoy's 5A media (Gibco, Shagrin Falls, $\mathrm{OH}$ ) to concentrations between 0.2 and $200 \mathrm{mM}$, adjusted with $1 \mathrm{~N} \mathrm{NaOH}$ to $\mathrm{pH}=7.35-7.42$, and passed through $0.45 \mu \mathrm{m}$ filters (Millipore Corp., Bedford, MA). Concentrations of glycine (JT Baker Chemical Co., Phillipsburg, NJ) between 2 and $150 \mathrm{mM}$, tiglic acid (Pfaltz and Bauer, Inc., Flushing, NY) between 0.2 and $20 \mathrm{mM}, 3-\mathrm{OH}$ PA (K \& K Lab, Inc., Plainview, NJ) between 0.2 and $20 \mathrm{mM}$ were prepared in a similar manner. PA was also prepared in phosphate buffer containing $2.4 \mathrm{mM} \mathrm{L}$-carnithine (Sigma-tau, Inc., Holmdel, NJ).

Human CFU-GM assays. Human CFU-GM were assayed in the presence of various concentrations of organic acids or serum using a modification of the double layer agar technique of Pike and Robinson (7) along with PCM as the source of CSA (8). BM samples were aspirated through the posterior iliac crest of normal adult donors following written informed consent as required by the Human Subjects Committee of the University of Colorado Health Sciences Center. MNC were obtained by centrifugation over Ficoll-Hypaque (density 1.077) (Isolymph, Gallard-Schlesinger Chem. Mfg. Corp., Carle Place, NY) at $400 \times g$ for $35 \mathrm{~min}$ followed by glass adherence for 1 to $2 \mathrm{~h}$ at $37^{\circ} \mathrm{C}$. A $1 \mathrm{ml}$ underlay of supplemented McCoy's 5A media with $15 \%$ fetal calf serum (Flow Laboratories, McLean, VA), 0.5\% agar (Bacto-Agar, Difco Labs, Detroit, MI) and 10\% PCM was added to 35-mm plastic Petri dishes (Falcon, Becton, Dickinson \& Co., Oxnard, CA), followed by a $1 \mathrm{ml}$ overlay of media, $0.3 \%$ agar, and $5 \times 10^{4} \mathrm{BM}$ MNC. A $10 \%$ volume of overlay media was replaced by patient or control sera. A $10 \%$ volume of either underlay or overlay media was replaced by an organic acid. Assays were performed in triplicate or quadruplicate, and with the exception of the assays testing sera, on several different $\mathrm{BM}$ samples. The cells were incubated for 14 days at $37^{\circ} \mathrm{C}, 7.5 \% \mathrm{CO}_{2}, 100 \%$ humidity. Colonies ( $>40$ cells) were counted with a dissecting microscope; random colonies were plucked from the agar and stained with orcein:acetic acid to verify the presence of polymorphonuclear cells.

In separate experiments, $1.4 \times 10^{6} \mathrm{BM} \mathrm{MNC}$ were incubated at $37^{\circ} \mathrm{C}, 7.5 \% \mathrm{CO}_{2}, 100 \%$ humidity, in media containing either $0,2,3$, or $5 \mathrm{mM} \mathrm{PA}$. After 24 or $48 \mathrm{~h}$ of preincubation the cells were washed twice, resuspended in media, and cultured as above at $7.5 \times 10^{4}$ cells/plate. Cell viability was determined by trypan blue dye exclusion.

Mouse CFU-E and CFU-GM assays. Mouse CFU-E and CFUGM were assayed using a modification of the fibrin clot technique of McLeod et al. (9). BM cells were flushed from tibia of CF1 mice with NCTC-109 (M. A. Bioproducts, Walkersville, MD). Culture media consisted of $10 \%$ detoxified solution of bovine serum albumin (Sigma, St. Louis, MO) prepared in Hank's MEM (Gibco, Grand Island, NY), 40\% NCTC-109 supplemented with L-asparagine, $\mathrm{CaCl}_{2}$, and transferrin, and $40 \%$ IMDM (Gibco) supplemented with cholesterol, egg yolk lecithin (Sigma), and antibiotics (10). For CFU-E, 10\% volume of NCTC109 with erythropoietin Step I (epo) (Connaught Medical Research Laboratory, Willowdale, Ontario, CA) was added, allowing for $0.125 \mathrm{U}$ epo/clot. For CFU-GM, $10 \%$ volume of kidney tubular conditioned media was used as the source of CSA. Media and cells $\left(2.7 \times 10^{5} / \mathrm{clot}\right)$ in a volume of $500 \mu \mathrm{l}$ were added to tissue culture cluster wells (Costar, Bellco, Vineland, NJ) and clotted with $50 \mu \mathrm{l}$ citrated bovine plasma (Colorado Serum Co., Denver, CO). A 5 or $10 \%$ volume of NCTC was replaced by organic acid or sera, respectively. The wells were incubated at $37^{\circ} \mathrm{C}, 5 \% \mathrm{CO}_{2}, 100 \%$ humidity, and harvested after 3 days for CFU-E and 6 days for CFU-GM. Clots were fixed on slides in glutaraldehyde. Erythroid colonies (at least 8 nucleated, benzidine positive cells) were counted at $100 \times$ and CFU-GM (at least 50 cells) were counted at $10 \times$ with a dissecting microscope. All assays were performed in triplicate or quadruplicate. 

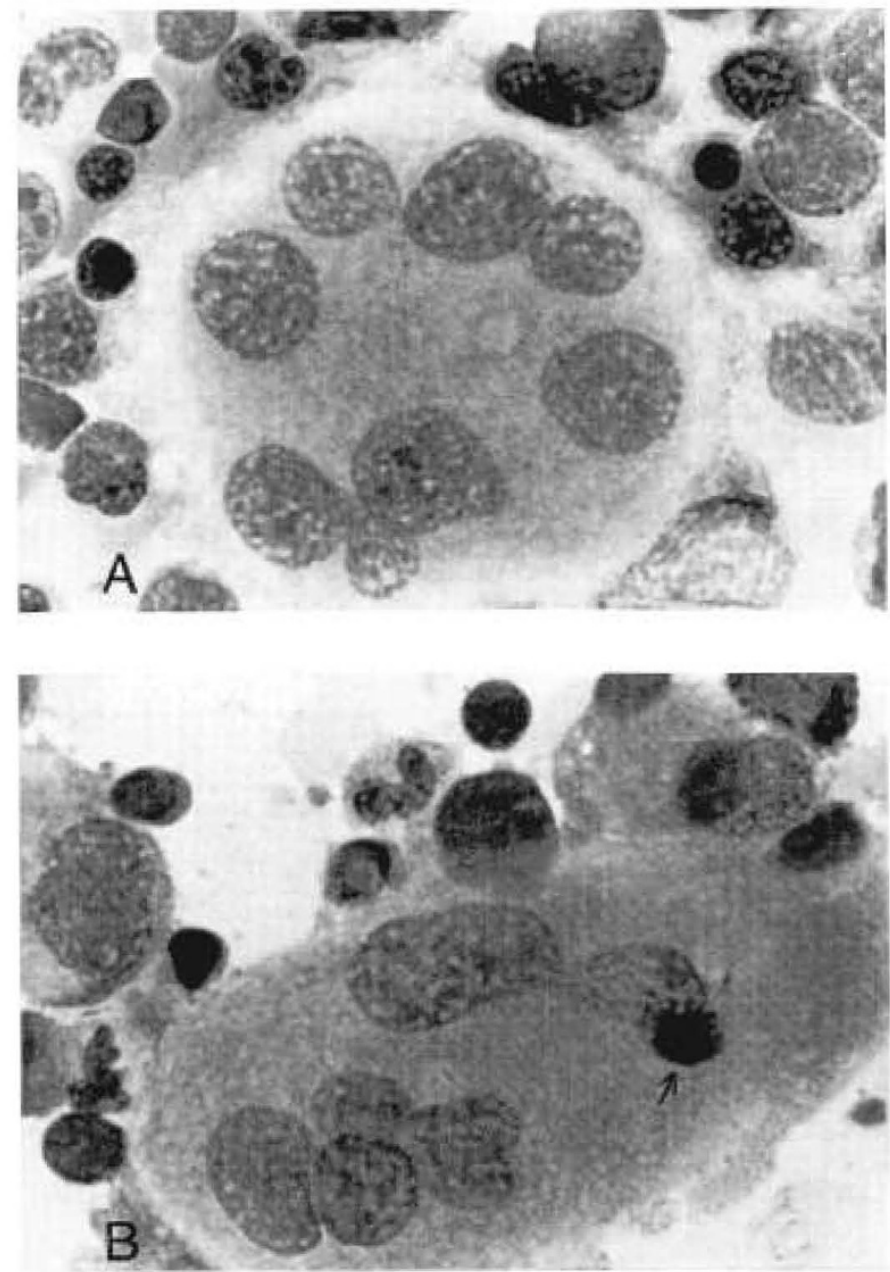

Fig. 2. Light microscopy of two multinucleated cells seen in the infant's BM aspirate (Wright's stain, oil emersion). A, cell appears to be of histiocytic origin and may have arisen from either cellular fusion or incomplete cellular division. B, cell is probably an abnormal megakaryocyte. A lymphocyte (arrow) appears attached to the cell surface.
Statistical methods. The Student's $t$ test was used to establish statistical significance.

\section{RESULTS}

Bone marrow histology and cytochemistry. The bone marrow aspirates and biopsies obtained at day 3 of presentation and day 1 of relapse were strikingly abnormal. Light microscopy revealed dysmyelopoiesis of erythroid, myeloid, and megakaryocytic cell lines along with mild megaloblastic changes. Cellularity was normal for age. Numerous large multinucleated cells (two to greater than ten nuclei) were present whose nuclear and cytoplasmic morphology suggested histiocytic, osteoclastic, and/or megakaryocytic cell types (Fig. 2). Lymphocytes appeared to be either attached to the surface of these cells or traveling intact through them (emperipolesis). The cytoplasm of some of the multinucleated cells stained light blue with Wright's stain; others stained pink and appeared very granular. The cells in question stained for both acid phosphatase and nonspecific esterase. The acid phosphatase was sensitive to tartrate inhibition, suggesting that these cells were not osteoclasts (11). Lysozyme positivity was found primarily in the binucleated cells of the clot preparation, while many of the larger cells remained unstained. Thus, some of these cells appeared to be histiocytes and others megakaryocytes. EM revealed histiocytes containing phagocytosed erythrocytes and remnants of nucleated cells. Markedly abnormal megakaryocytes, containing dilated demarcation membrane systems, focal disruption of the cytoplasmic architecture, and intracytoplasmic aggregates of electron dense material were also observed (Fig. 3). Lymphocytes were found attached to cell membranes but not engaged in emperipolesis. The bone marrow aspirate of day 11 revealed very few multinucleated cells, minimal dysmyelopoiesis, and increased numbers of normal megakaryocytes.

Colony growth in the presence of sera and organic acids. As shown in Figure $4 A$, the presence of $10 \%$ infant serum decreased mouse erythroid colony formation by $43 \%$ compared with normal human sera. This difference was statistically significant $p<$ 0.05 . The number of mouse CFU-GM was reduced by $32 \%$ in the presence of her serum (Fig. $4 B$ ) but this did not reach statistical significance, $p<0.1$, compared with controls. However, the presence of $5 \%$ infant serum, added to the overlay, dir not alter human granulocytic colony formation (Fig. $4 C$ ).
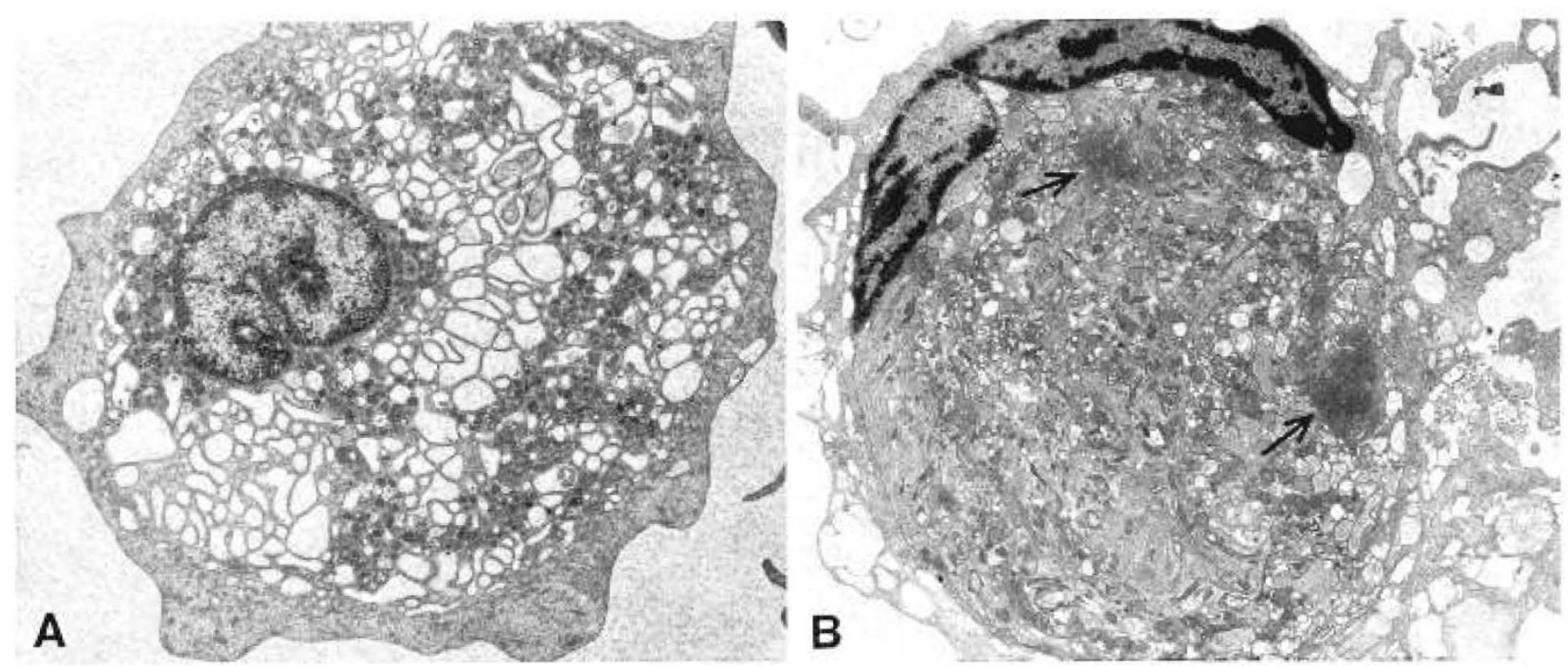

Fig. 3. EMs of two abnormal megakaryocytes found in the infant's BM specimen $(\times 4500)$. $A$, dilated demarcation membrane systems, $B$, disrupted cytoplasmic architecture, and electron dense inclusions (arrows) are evident. 


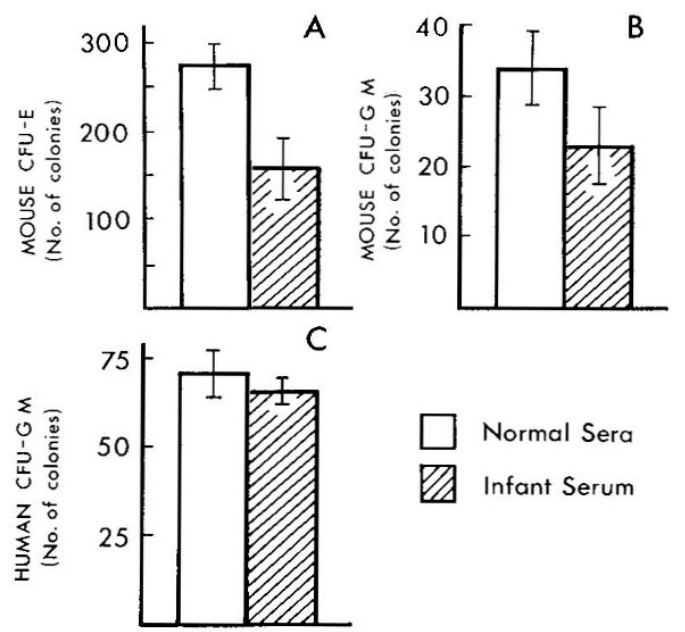

Fig. 4. Effect of infant's serum on mouse CFU-E, CFU-GM, and human CFU-GM. $A$ and $B$, Mouse BM cells $\left(2.7 \times 10^{5} /\right.$ well $)$ were assayed in the presence of either $10 \%$ normal sera or $10 \%$ infant's serum. $C$, human BM MNC $\left(5 \times 10^{4} /\right.$ plate $)$ were assayed in the presence of either $5 \%$ normal human sera or $5 \%$ infant's serum. Data for normal sera represent mean colony count \pm SEM of 5 sera, each plated in quadruplicate, including two age-matched controls. Data for infant serum represent mean colony count \pm SEM of quadruplicate assays. Reduction of CFU-E was statistically significant, $p<0.05$.

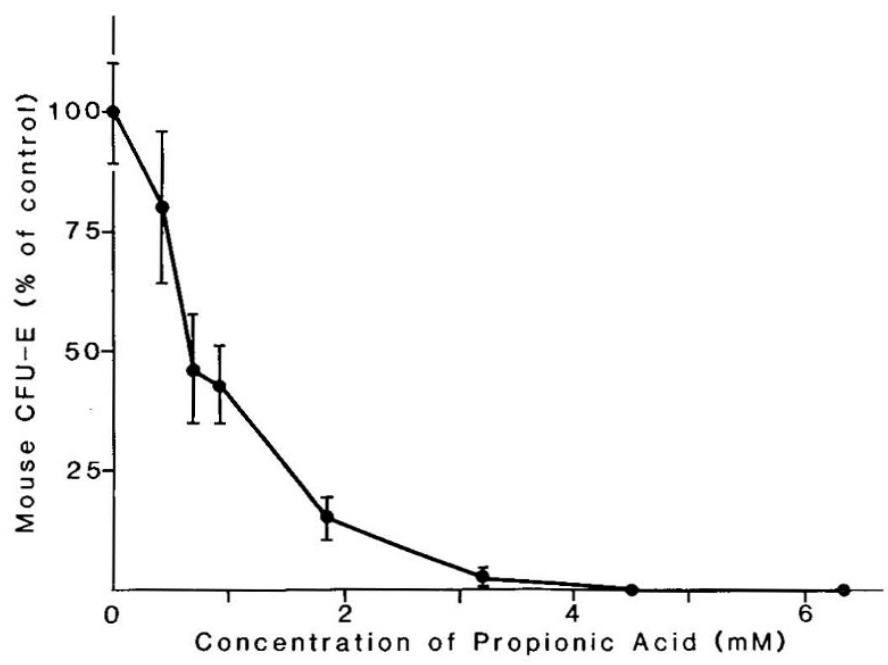

Fig. 5. Effect of PA on mouse CFU-E. Mouse BM cells were assayed in the presence of PA, adjusted to physiologic $\mathrm{pH}$, at the above final concentrations. Results are from one of two separate experiments. Data represent mean colony count $\pm \operatorname{SEM}(n=4)$ as percent of control colony count ( $0 \mathrm{mM} \mathrm{PA})$, the latter arbitrarily set at $100 \%$.

Certain organic acids associated with propionic acidemia were added in vitro to BM colony assays. As shown in Figures 5 and 6, PA inhibited growth of mouse CFU-E and human CFU-GM in a concentration-dependent manner. Interestingly, the lower concentrations of PA significantly stimulated growth of human CFU-GM. Also noteworthy is that addition of PA to the underlay rather than overlay of double layer agar culture shifted the $50 \%$ inhibitory concentration from 1.6 to $6.8 \mathrm{mM} \mathrm{PA}$. The percent inhibition of mouse CFU-E and human CFU-GM observed at each concentration of PA was not significantly altered by addition of $120 \mu \mathrm{M} \mathrm{L}$-carnitine, the total serum level attained in the infant while on supplemental L-carnitine (percent inhibition of CFU-E at $0.68 \mathrm{mM}$ PA: alone, $54 \pm 12 \%$; with L-carnitine, 43 $\pm 5 \% ; 100 \%$ inhibition at $4.5 \mathrm{mM} \mathrm{PA}$, alone and with $\mathrm{L}-$

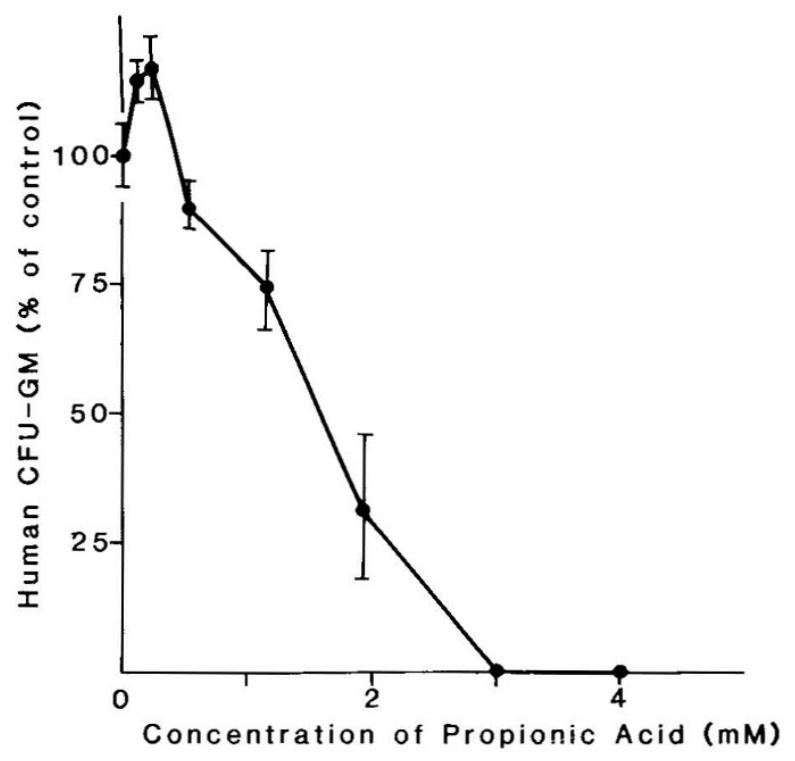

Fig. 6. Effect of PA on human CFU-GM. Human BM MNC were cultured in the presence of buffered PA added at the above final concentrations to the overlay of double layer agar culture. Results are from one of three similar experiments. Data represent mean colony count \pm SEM $(n=3$ or 4$)$ as percent of control colony count $(0 \mathrm{mM} \mathrm{PA})$, the latter arbitrarily set at $100 \%$.

carnitine. Percent inhibition of CFU-GM at $7 \mathrm{mM}$ PA: alone, $55.5 \pm 14 \%$; with L-carnitine, $43 \pm 4 \%$; $100 \%$ inhibition at 10 $\mathrm{mM}$ PA, alone and with L-carnitine).

Neither glycine $(0.01-5 \mathrm{mM})$, tiglic acid $(0.01-1 \mathrm{mM})$, nor 3OH PA (0.01-1 mM) had any inhibitory effect on mouse CFUE, CFU-GM, or human CFU-GM at clinically relevant concentrations (data not shown). In fact, the addition of glycine ( 0.5 to $5 \mathrm{mM}$ ) significantly enhanced growth of human CFU-GM (data not shown).

To distinguish between growth inhibition and cytotoxicity of PA on granulocyte progenitors, the viability and colony formation of human BM MNC was assessed following incubation with $0,2,3$, and $5 \mathrm{mM}$ PA. Cell viability was $>96 \%$ after 24 and 48 $\mathrm{h}$ of incubation at all concentrations. Subsequent colony formation of cells preincubated with 2,3 , and $5 \mathrm{mM}$ PA was equivalent to or modestly greater than that of cells preincubated without the acid. [CFU-GM, as percent of control (0 mM PA), for cells preincubated with $5 \mathrm{mM}$ PA was $141 \%$ and $100 \%$ at 24 and 48 hours, respectively.]

\section{DISCUSSION}

Infants with propionic acidemia lack activity of the mitochondrial enzyme propionylCoA carboxylase, which is required to catabolize a number of amino acids, cholesterol, and odd-chain fatty acids prior to entry into the tricarboxylic acid cycle. PA (propionylCoA), a three-carbon fatty acid, and often glycine, accumulate in the sera and tissues of these infants, while a number of abnormal organic acids, including tiglic acid and 3OH PA, are excreted in their urine (12). Serum levels of PA as high as $5.4 \mathrm{mM}$ (13) and glycine as high as $1.6 \mathrm{mM}$ (14) have been observed in acutely ill infants. Urinary levels of tiglic acid and 3-OH PA greater than one hundred times normal have been reported, although tissue and serum levels are significantly less elevated due to the rapid renal clearance of these compounds $(14,15)$. Infants with propionic acidemia frequently develop neutropenia, thrombocytopenia, and, occasionally, anemia (16). Most have concomitant acidosis.

Our patient presented with pancytopenia and markedly disturbed bone marrow morphology while she was neither acidotic 
nor hyperammonemic. Prior to the biochemical documentation of propionic acidemia, diagnostic possibilities entertained to explain the dysmyelopoiesis, hemophagocytosis, and large multinucleated cells seen in her BM aspirate included viral induced hemophagocytosis and familial erythrophagocytic lymphohistiocytosis (17). The observed BM abnormalities have not been previously described in association with propionic acidemia, and, to our knowledge, the numerous multinucleated histiocytes and megakaryocytes have not been previously described in any bone marrow disorder.

The child improved clinically with dietary management, and when her initial urinary excretion of 3-OH PA had decreased by $50 \%$, the pancytopenia and BM dysplasia were resolved. The hematologic abnormalities recurred several months later in the face of clinical deterioration and increased urinary excretion of organic acids. The twice-coincident onset of lethargy and pancytopenia suggested that one or several substances accumulating in this child were responsible for her hematologic abnormalities. It seemed doubtful that concomitant viral infections caused both episodes of marrow dysplasia since, in addition to negative viral cultures, the pancytopenia resolved rapidly with dietary management alone. Therefore, we evaluated the effects of the infant's serum and of certain organic acids associated with propionic acidemia on erythroid and granulocyte-monocyte colony formation, using the mouse and human culture systems available to us at the time.

The presence of the infant's serum, obtained while pancytopenic, reduced mouse erythroid and granulocyte-monocytic colony formation by 43 and $32 \%$, respectively, compared with normal sera. The former but not the latter decrease reached statistical significance. However, her serum did not inhibit growth of human CFU-GM. When buffered propionic acid was added to mouse erythroid and human granulocytic cultures, concentration-dependent growth inhibition occurred over a range found in sera of acutely ill infants. L-Carnitine did not alter this inhibition. PA was not directly cytotoxic to human BM MNCs. These cells remained viable following $48 \mathrm{~h}$ of incubation with buffered PA, and normal colony formation occurred when the preincubated cells were washed and assayed for CFU-GM. The three other organic acids studied, tiglic acid, 3-OH PA, and glycine, did not inhibit colony formation at clinically relevant concentrations, and glycine significantly enhanced human CFUGM.

Although the relationship between the in vitro and in vivo effects of PA remains to be clarified, our in vitro observations implicate PA in the infant's hematopoietic dysfunction. PA may have reversibly inhibited the proliferation and maturation of her bone marrow stem cells in a concentration-dependent manner, thus allowing for her rapid recovery as serum and tissue levels of PA increased. The lack of complete inhibition by her serum on mouse colony formation and the absence of inhibition on human colony growth may be accounted for in several ways. First, the infant's serum comprised only $10 \%$ of the mouse culture media and $5 \%$ of the human double layer agar culture, allowing significant dilution of the putative $\mathrm{PA}$ in vitro. In addition, her serum may have contained hematopoietic stimulators responding to her pancytopenia that countered the inhibitory effect of PA in culture. Furthermore, the normal BM cells used in culture were likely more resistant than the infant's cells to the same concentrations of PA, since the former cells could metabolize some of the excess acid. Unfortunately, due to technical difficulties at the time of her relapse, we were unable to assay the infant's BM progenitors in the presence of PA.

PA may have had additional hematologic effects in our patient. At presentation her peripheral red blood cell morphology was notable for anisocytosis and poikilocytosis which disappeared following clinical improvement. At relapse, her $\mathrm{Hgb}$ fell by $4 \mathrm{~g} /$ $\mathrm{dl}$ in 5 days, in the absence of detectable blood loss. A similar decline in $\mathrm{Hgb}$ was noted by Kelleher et al. (3) in a patient with isovaleric acidemia. Gompertz et al. (18) analyzed the red cell membranes of an infant with propionic acidemia and found them to contain three to five times more 15- and 17-carbon fatty acids than normal. Oizumi et al. (19) showed that these same fatty acids accumulated in cultured skin fibroblasts of two patients with propionic acidemia. It is possible that changes in membrane lipid composition or increased intracellular PA resulted in diminished survival of the infant's red blood cells. The erythrophagocytosis seen in her marrow may have been, in part, in response to abnormal red cells.

Propionic acidemia may offer clinical relevance to the effects previously observed in vitro with both propionate and butyrate (a four-carbon fatty acid). Both these compounds have been found to inhibit growth of bacteria, HeLa cells (20), and chick embryo fibroblasts (21), to reversibly inhibit histone deacetylase $(22,23)$, and to modify growth-related processes of several transformed cell lines $(24,25)$. Butyrate has been shown to arrest cell growth at $G_{1}$ phase of cell cycle (26), to alter size and shape of rabbit articular chondrocytes with formation of binucleated cells (27), and to disrupt nuclear and cytoskeletal elements of several cell types (28). Taken together, the present investigation, the study by Inoue et al. (4) of an infant with methylmalonic acidemia and pancytopenia, and the report by Hutchinson et al. (5) concerning inhibition of granulopoiesis by metabolites of branched-chain amino acids, suggest that excess organic acids may be directly responsible for the cytopenias observed in several inborn errors of amino acid metabolism, including isovaleric, methylmalonic, and propionic acidemias.

Acknowledgments. The authors are grateful to Rita Vautrin for her technical assistance, to Drs. John Paisley and Stephen Goodman for helping to establish the diagnosis, and to Dr. William A. Robinson for his thoughtful assistance.

\section{REFERENCES}

1. Sweetman L, Nyhan WL 1979 Propionic acidaemia presenting with pancytopaenia in infancy. J Inherited Metab Dis 2:65-69

2. Mahoney MJ 1976 Organic acidemias. Clin Perinatol 3:61-78

3. Kelleher JF, Yudkoff M, Hutchinson R, August CS, Cohn RM 1980 The pancytopenia of isovaleric acidemia. Pediatrics 65:1023-1026

4. Inoue S, Krieger I, Sarnaik A, Ravindranath Y, Fracassa M, Ottenbreit MJ 1981 Inhibition of bone marrow stem cell growth in vitro by methylmalonic acid: a mechanism for pancytopenia in a patient with methylmalonic acidemia. Pediatr Res 15:95-98

5. Hutchinson RJ, Bunnell K, Thoene JG 1985 Suppression of granulopoietic progenitor cell proliferation by metabolites of the branched-chain amino acids. J Pediatr 106:62-65

6. Roe CR, Bohan TP 1982 L-Carnitine therapy in propionicacidaemia. Lancet $1: 1411-1412$

7. Pike BL, Robinson WA 1970 Human bone marrow colony growth in agar-gel. $J$ Cell Physiol 76:77-84

8. Burgess AW, Wilson EMA, Metcalf D 1977 Stimulation by human placental conditioned medium of hemopoietic colony formation by human marrow cells. Blood 49:573-583

9. McLeod DL, Shreeve MM, Axelrad AA 1974 Improved plasma culture system for production of erythrocytic colonies in vitro: quantitative assay method for CFU-E. Blood 44:517-534

10. Wallner S, Vautrin R, Murphy J, Anderson S, Peterson V 1984 The haematopoietic response to burning: studies in an animal model. Burns 10:236251

11. Sun T, Li C-Y, Yam LT 1985 Atlas of Cytochemistry and Immunochemistry of Hematologic Neoplasms. American Society of Clinical Pathologists Press, Chicago, pp 26-28, 36-37

12. Rosenberg LE 1983 Disorders of propionate and methylmalonate metabolism. In: Stanbury JB (ed) The Metabolic Basis of Inherited Disease. McGrawHill, New York, pp 474-497

13. Hommes FA, Kuipers JRG, Elema JD, Jansen JF, Jonxis JHP 1968 Propionicacidemia, a new inborn error of metabolism. Pediatr Res 2:519-524

14. Ando T, Nyhan WL 1974 Propionic acidemia and the ketotic hyperglycinemia syndrome. In: Nyhan WL (ed) Heritable Disorders of Amino Acid Metabolism: Patterns of Clinical Expression and Genetic Variation. Wiley, New York, pp 37-60

15. Bergstr $\phi \mathrm{m}$ T, Greter J, Levin A, Steen G, Tryding N, Wass U 1981 Propionyl$\mathrm{CoA}$ carboxylase deficiency: case report, effect of low-protein diet and idenyification of 3-oxo-2-methylvaleric acid 3-hydroxy-2-methylvaleric acid, and maleic acid in urine. Scand J Clin Lab Invest 41:117-126

16. Wolf B, Hsia E, Sweetman L, Gravel R, Harris DJ, Nyhan WL 1981 Propionic acidemia: a clinical update. J Pediatr 99:835-846

17. Perry MC, Harrison EG, Burgert EM, Gilchrist GS 1976 Familial erythro- 
phagocytic lymphohistiocytosis, report of two cases and clinicopathologic review. Cancer 38:209-218

18. Gompertz D, Storrs CN, Bau DCK, Peters TJ, Hughes EA 1970 Localisation of enzymic defect in propionicacidaemia. Lancet 1:1140-1143

19. Oizumi J, Giudici TA, Ng WG, Shaw KNF, Donnell GN 1981 Propionate metabolism by cultured skin fibroblasts from normal individuals and patient with methylmalonicaciduria and propionicacidemia. Biochem Med 26:2840

20. Sheu CW, Salomon D, Simmons JL, Sreevalsan T, Freese E 1975 Inhibitory effects of lipophilic acids and related compounds on bacteria and mammalian cells. Antimicrob Agents Chemother 7:349-363

21. Hagopian HK, Riggs MG, Swartz LA, Ingram VM 1977 Effect of n-butyrate on DNA synthesis in chick fibroblasts and HeLa cells. Cell 12:856-860

22. Sealy L, Chalkley R 1978 The effect of sodium butyrate on histone modification. Cell 14:115-12
23. Cousens LS, Gallwitz D, Alberts BM 1979 Different accessibilities in chromatin to histone acetylase. J Biol Chem 254:1716-1723

24. McKnight GS, Hager L, Palmiter RD 19870 Butyrate and related inhibitors of histone deacetylation block the induction of egg white genes by steroid hormones. Cell 22:469-477

25. Samuels HH, Stanley F, Casanova J, Shao TC 1980 Thyroid hormone nuclear receptor levels are influenced by the acetylation of chromatin-associated proteins. J Biol Chem 255:2499-2508

26. Wintersberger E, Mudrak I, Wintersberger U 1983 Butyrate inhibits mouse fibroblasts at a control point in the $G_{1}$ phase. J Cell Biochem 21:239-247

27. Larno S, Ronot X, Adolphe M, Lechat P 1984 Effects of sodium butyrate on growth and cell-cycle kinetics of cultured rabbit articular chondrocytes. J Cell Physiol 120:384-390

28. Kruh J 1982 Effect of sodium butyrate, a new pharmacological agent, on cells in culture. Mol Cell Biochem 42:65-82 